\title{
Study on Emission Characteristics Test of Diesel Engine Operating on Diesel/Methanol Blends
}

\author{
Yuanhua Jia ${ }^{1, \text { a }}$, Guifu Wu ${ }^{2, b}$, Enhui Xing ${ }^{3, c}$, Ping Hang ${ }^{4, d}$, Wanjiang Wu ${ }^{5 e}$ \\ 1,2,3, 4,5 College of Mechanical Engineering Jiamusi University Jiamusi, 154007China \\ ajyhteacher@163.com, bwgfteacher@126.com, \\ cxingeh@163.com, ${ }^{\mathrm{d}}$ hanping_jtys@163.com, ${ }^{\mathrm{e}}$ wwj710919@163.com,
}

Keywords: diesel engine; ethanol diesel; emission characteristic

Abstract: Study the effects of diesel engine emission characteristics with different adding proportions of ethanol on a DI diesel engine. The results show that with the increasing of ethanol blending proportions, the diesel exhaust gas decreases with the addition of ethanol, the emission of NOX also reduces significantly, but $\mathrm{HC}$ and $\mathrm{CO}$ increase significantly.

\section{Introduction}

With the increasing of vehicle's possessive quantity and the decreasing of oil reserves, oil crisis warns people that please save energy increasingly. Compared with gasoline engine, diesel engine has a higher thermal efficiency and a wider range of applications. This urges a lot of researchers have made the long-term commitment to the study of improving disel engine characteristics. However, the development of diesel has always been restricted from emissions problem. In recent years, due to the further strengthening awareness of environmental protection and the gradually stricter emission regulations, reducing diesel emissions have become a major research direction. Ethanol as a biofuel which contains oxygen, Gasoline or diesel fuel blended with ethanol can greatly reduce the pollutant emissions., especially in diesel engine. According to the results of preliminary test, adding ethanol to diesel oil can reduce the emissions of smoke.

Ethanol is very difficult to be miscible with diesel oil directly. With the constant advancements of technological, States have developed a low-cost additive in succession to solve the intersolubility, lubricity, corrosion and other problems between diesel oil and ethanol, which make massive using of diesel/methanol blends possible. By comparing ethanol's physicochemical properties with diesel oil's in this article, it focuses on the emission characteristics of diesel/methanol blends blended with two different proportions of ethanol 10\% (E10) and 20\% (E20).

\section{Test Equipments and Fuel Properties}

The test was making on a single-cylinder horizontal water-cooled DI diesel engine. The bore and stroke both are $115 \mathrm{~mm}$, the compression ratio is 17 , the combustion chamber is $\omega$ type, the rated power/speed is $14.7 \mathrm{kw} /(2200 \mathrm{r} / \mathrm{min})$.The test equipments are FGA4015 five-gas analysis meter, AVLDisomke400 smoke opacimeter, electric eddy current dynamometer, transient fuel gauge and so on.

The comparison between ethanol's physical parameters and diesel oil's is given in table 1. The test use \#0 diesel oil and ethanol mixed in a certain volume percentage. The ethanol addition ratio are $0 \%, 10 \%$ and $20 \%$. During the test, the engine burned blending fuel with different proportions of ethanol, and measured their emission parameters. 
Tab.1 Main physicochemical properties of ethanol and diesel oil

\begin{tabular}{|c|c|c|}
\hline & Diesel oil & Ethanol \\
\hline Chemical formula & $\mathrm{C}_{16} \mathrm{H}_{34}$ & $\mathrm{CH}_{3} \mathrm{CH}_{2} \mathrm{OH}$ \\
\hline Lower heating value $(\mathrm{MJ} / \mathrm{kg})$ & 42.5 & 27.0 \\
\hline Density $(\mathrm{g} / \mathrm{ml})$ & 0.84 & 0.81 \\
\hline Cetane number & $40 \sim 55$ & 8 \\
\hline Self-ignition temperature $\left({ }^{\circ} \mathrm{C}\right)$ & 250 & 420 \\
\hline Octane number & - & 108 \\
\hline Equivalent air-fuel ratio & 14.6 & 9.0 \\
\hline Boiling point $\left({ }^{\circ} \mathrm{C}\right)$ & $180 \sim 370$ & 78 \\
\hline Viscosity $\left(\mathrm{Pa}, \mathrm{s}, 20^{\circ} \mathrm{C}\right)$ & 3.7 & 1.2 \\
\hline Evaporation value $(\mathrm{kJ} / \mathrm{kg})$ & 250 & 904 \\
\hline
\end{tabular}

From table 1, we can see that ethanol has high oxygen content, big latent heat of vaporization, high self-ignition temperature, low heating value and lower cetane number. Therefore, the combustion temperature in cylinder is lower when blended with ethanol in diesel engine. Since the ethanol fuel's "oxygenate" feature, the required air when combusing is only about half the diesel's theoretically. This has a positive effect on the improvement of soot and particles which are generated due to uneven mixing of oil and gas in diffusion combustion.

\section{Test Results and Analysis}

\section{Effect of Ethanol's Proportion on HC Emissions}

Figure 1 illustrates the emissions of $\mathrm{HC}$ when engine fueled with diesel/methanol blends blended with different proportions of ethanol. From the figure 1, we can see that the HC emissions of diesel/methanol blends is higher than the pure diesel's under low load conditions, and with the increasing of ethanol proportion in blending fuel, the emissions of HC rises. This is because that the effect of ethanol's latent heat of vaporization plays a leading role under low load conditions. The increasing of ethanol results in the prolonging of the ignition delay, the over dilute zone's increasing of spray and the increasing of HC emissions. As the load increases, the fuel delivery increases. This makes the combustion temperature in cylinder rise and in favor of the oxidation reaction of $\mathrm{HC}$, so $\mathrm{HC}$ decreases with the increasing of the load. In summary, blending with ethanol can result in the increasing of $\mathrm{HC}$ emissions, and with the increasing of the blending proportion, the emissions of HC increases. This is because that the ethanol's latent heat of vaporization is higher than diesel oil's. So blending with ethanol can decrease the combustion temperature in cylinder. It is not conducive to the oxidation reaction of $\mathrm{HC}$, so the emissions increases. 


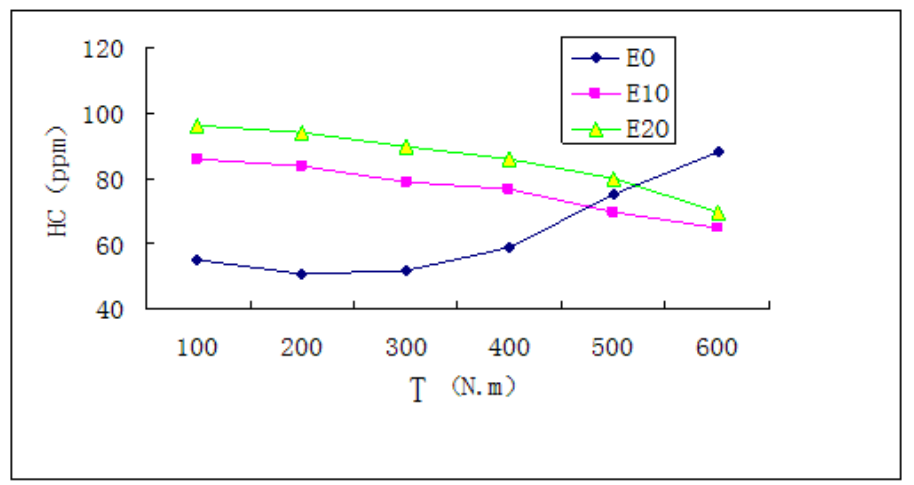

Fig.1 The influence of blend fuel of ethanol and diesel on $\mathrm{HC}$ emission

\section{Effect of Ethanol's Proportion on CO Eemissions}

From figure 2, we can see that the $\mathrm{CO}$ emissions of diesel/methanol blends is lower than the diesel oil's under the middle high load with $1400 \mathrm{r} / \mathrm{min}$. And the $\mathrm{CO}$ emissions of diesel oil is the lowest under the low load. This is because the combustion temperature in cylinder is lower under low load condition. Because of the higher latent heat of vaporization of ethanol, the combustion temperature in cylinder under the low load condition further reduce, and reduce the oxidation rate of CO. So the higher latent heat of vaporization of ethanol results in the thicker layer of flame quenching. And this is the main reason of the over high $\mathrm{CO}$ emissions of blending fuel under the low load condition. However, with the increasing of the load, cylinder temperature increases gradually. It helps undermine ethanol fuel quenching effect, meanwhile, the ethanol is oxygenated fuel which helps improve the oxidation rate of $\mathrm{CO}$. This improve the $\mathrm{CO}$ emissions of blending fuel under the high load condition.

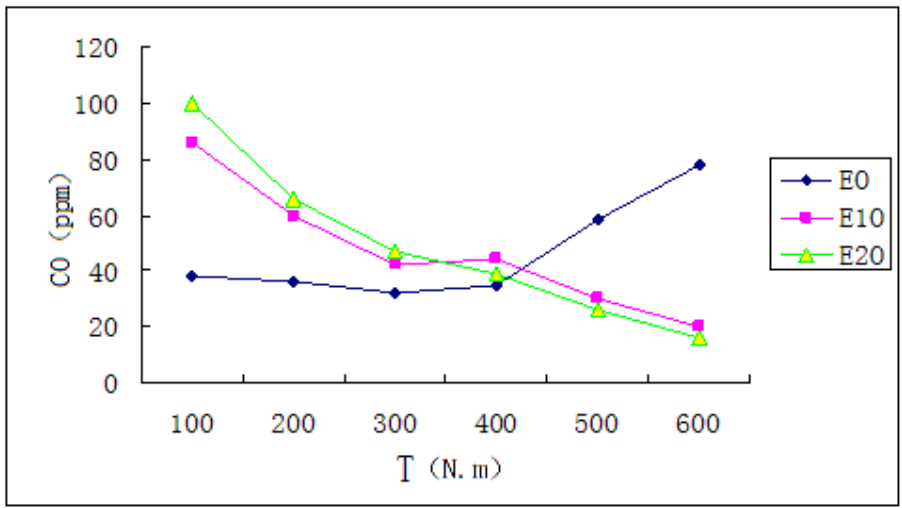

Fig.2 The influence of blend fuel of ethanol and diesel on $\mathrm{CO}$ emission

\section{Effect of Ethanol's Proportion on NOx Emissions}

Figure 3 gives the NOx emissions of blending fuel with different ethanol proportions. From figure 3, we can see that compared with diesel oil, the NOx emissions of diesel/methanol blends reduces obviously. And the larger ethanol blending proportion, the greater reduction of NOx it is. This is because with the increasing of blending proportion, the ethanol content increases, the heat required for fuel evaporation increases, the combustion temperature is lower. It can also results in the prolonging of the ignition delay and the reduction of NOx emissions. 


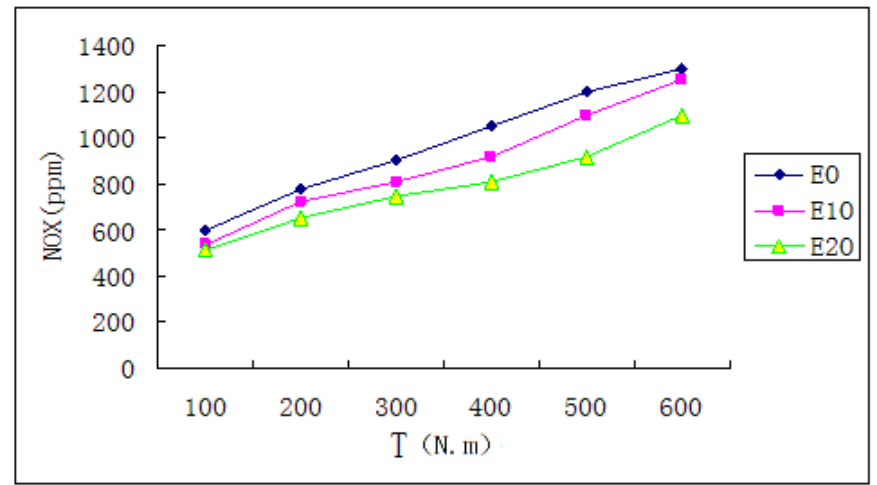

Fig.3The influence of blend fuel of ethanol and diesel on NOx emission

\section{Effect of Ethanol's Proportion on Soot Emissions}

Figure 1 illustrates the emissions of soot when engine fueled with blending fuel blended with different proportions of ethanol. From it, we can see that the smoke emissions of diesel/methanol blends is lower than the diesel oil's, and the larger proportion of ethanol in blending fuel, the lower emissions of smoke, especially under the low speed high load condition. This is because with the increasing of ethanol proportion in blending fuel, the oxygen content of the blending fuel increases, and the lower boiling point and viscosity of ethanol make fuel mix with air more easily. Reducing over rich mixture combustion region makes the combustion more fully, thereby reducing the smoke emissions. Otherwise, it is generally believed that pyrolysis of polymer hydrocarbons (particularly aromatic hydrocarbons) under anoxic condition inside the combustion chamber results in the generation of smoke. Ethanol doesn't contain aromatic hydrocarbons, so the increasing of ethanol proportion in blending fuel reduces the aromatic hydrocarbons content in blending fuel. This reduces the smoke emissions.

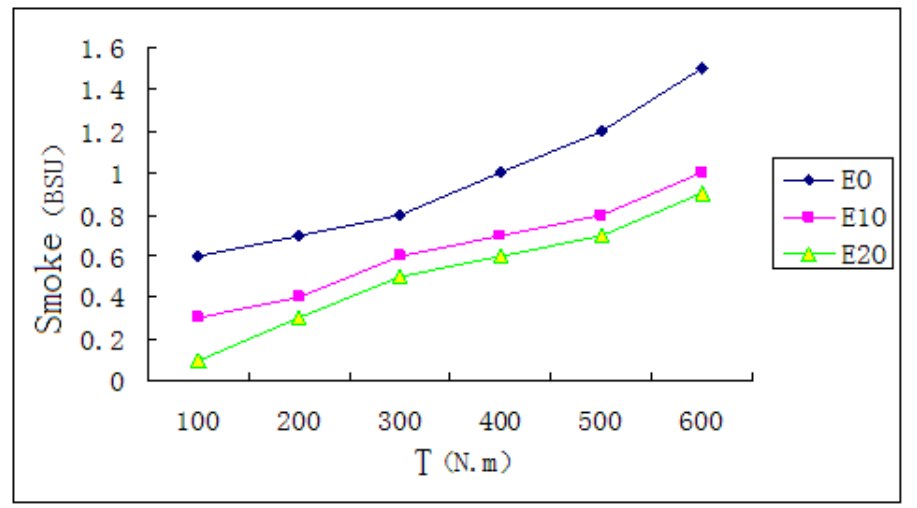

Fig.4The influence of blend fuel of ethanol and diesel on smoke emission

\section{Conclusions}

(1)Compared with diesel oil, the soot emissions of diesel/methanol blends is lower. The larger ethanol proportion in blending fuel, the lower smoke emissions there are.

(2)The $\mathrm{HC}$ emissions of diesel/methanol blends is higher than the pure diesel's. The larger ethanol proportion in blending fuel, the higher $\mathrm{HC}$ emissions there are.

(3) The CO emissions of diesel/methanol blends is lower than the pure diesel's under the middle high load condition. The CO emissions of diesel/methanol blends is higher than the pure diesel's under the low load condition.

(4)With the increasing of ethanol proportion, NOx emissions reduces. 


\section{Acknowledgment}

This work has been supported by scientific research fund of Jiamusi University (NO:L2012-013) and we acknowledge their fund

\section{References:}

[1]Lv Xingcai, Li Degang, Yang Jianguang, etal. Combustion and Emission Characteristics of Diesel Engine Operating on Ethanol/Diesel Blends[J]. Automobile Engineering, 2004,26(2):18 22.

[2]Matti M. Echase R. The Effect of Dimethoxy Methane Additive on Diesel Vehicle Particulate Emissions. SAE Paper,1998,982572[R]. Washington,USA: Society of Automotive Engineers Inc, 1998

[3]Huang Zuohua, Lu Hongbing, Jiang Deming. Study on Combustion Characteristics of a DI Diesel Engine Operating on Diesel/Methanol Blends[J] .Transactions of CSICE, 2003, 21(6):401 -410 .

[4] Wang Jianxin, Yan Xiaoguang, Cheng Yong, etal. Investigation on Combustion and Emissions Characteristics of Ethanol Diesel Blend Fuel[J].Transactions ofCSICE, 2002, 20( 3 ):225 -229. 